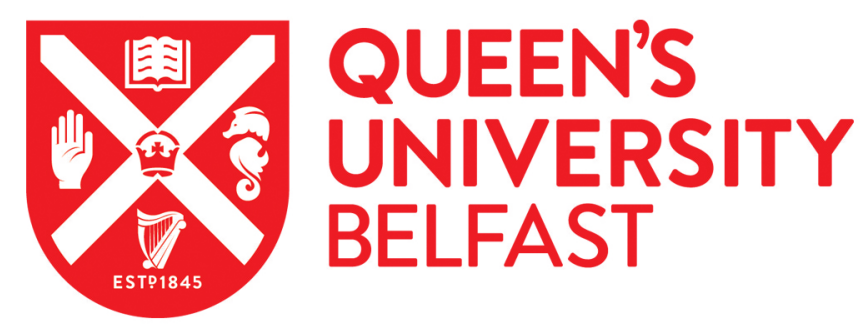

\title{
Squinted Elevation Antenna for Ku Band DVB Satellite Reception with Electronically Steered Azimuth
}

\author{
Buchanan, N. B., Fusco, V. F., \& Pal, A. (2017). Squinted Elevation Antenna for Ku Band DVB Satellite \\ Reception with Electronically Steered Azimuth. In Proceedings of the 11th European Conference on Antennas \\ and Propagation (EuCAP) Institute of Electrical and Electronics Engineers Inc.. \\ https://doi.org/10.23919/EuCAP.2017.7928538
}

Published in:

Proceedings of the 11th European Conference on Antennas and Propagation (EuCAP)

\section{Document Version:}

Peer reviewed version

Queen's University Belfast - Research Portal:

Link to publication record in Queen's University Belfast Research Portal

\section{Publisher rights}

(c) 2016 IEEE. Personal use of this material is permitted. Permission from IEEE must be obtained for all other uses, in any current or future media, including reprinting/republishing this material for advertising or promotional purposes, creating new collective works, for resale or redistribution to servers or lists, or reuse of any copyrighted component of this work in other works.

\section{General rights}

Copyright for the publications made accessible via the Queen's University Belfast Research Portal is retained by the author(s) and / or other copyright owners and it is a condition of accessing these publications that users recognise and abide by the legal requirements associated with these rights.

Take down policy

The Research Portal is Queen's institutional repository that provides access to Queen's research output. Every effort has been made to ensure that content in the Research Portal does not infringe any person's rights, or applicable UK laws. If you discover content in the Research Portal that you believe breaches copyright or violates any law, please contact openaccess@qub.ac.uk. 


\title{
Squinted Elevation $\mathrm{K}_{\mathrm{u}}$ Band Antenna for DVB Satellite Reception with Electronically Steered Azimuth
}

\author{
N.B Buchanan, V.F. Fusco, \\ The Institute of Electronics, Communications and Information Technology (ECIT, Queen's University Belfast, Northern Ireland \\ Science Park, Queen's Road, Queen's Island, Belfast, United Kingdom, BT3 9DT, Tel +44 2890971721 , Fax +44 2890971702 \\ n.buchanan@ecit.qub.ac.uk \\ v.fusco@ecit.qub.ac.uk
}

\begin{abstract}
This paper describes a Ku band, electronic beam steered array, operating at $10.7 \mathrm{GHz}$ to $12.7 \mathrm{GHz}$ intended for satellite DVB reception. The beam steering operates in the azimuth plane and the antenna also has a fixed beam squint at 23 elevation selected as appropriate for UK. This allows the distinct advantage of the antenna having the ability to be mounted vertically on a wall, by virtue of its fixed elevation angle. Therefore the mounting can be very discrete, with less than $1 \mathrm{~cm}$ protrusion from a wall in comparison to much bulkier parabolic dish antenna solutions. The relative simplicity and low profile of the antenna has been made possible by the use of COTS Ku band IC's, combined with novel analogue IF beamforming circuits. The antenna has been shown to be capable of receiving commercial DVB satellite signals transmitted from the Astra satellite in the UK. The antenna has dimensions of $25 \times 37 \mathrm{~cm}$ and is less than $1 \mathrm{~cm}$ thick. It has a measured $\mathrm{G} / \mathrm{T}$ of $7 \mathrm{~dB} / \mathrm{K}$.
\end{abstract}

Index Terms - Phased arrays, adaptive arrays

\section{INTRODUCTION}

There have been a number of planar Ku band antennas reported for satellite TV reception since $\mathrm{Ku}$ band satellite broadcasting began in the 1980's. Perhaps one of the best known of these antennas in the UK was the "Squarial" [1]. This was a planar phased array type antenna and operated on circular polarisation. It did not have any beam steering circuits, so had to be orientated at normal incidence to the satellite signal, meaning that it had to be mounted a distance offset from the wall and manually aligned in both azimuth and elevation onto the service providing satellite of interest. It was therefore no less unobtrusive than the ubiquitous reflector type antenna that is still commonly used for satellite reception. Various other flat $\mathrm{K}_{\mathrm{u}}$ band antenna publications [2-4] have appeared but none have realized commercial traction largely due to the same alignment and mounting requirements of the Squarial. These reported antennas have made use of various technologies ranging from microstrip patch arrays to leaky wave antenna waveguide structures.

Looking at the possibility of producing a phased array for satellite reception in the context of recently available technology, allows for new opportunities that were not available at the times of the previously mentioned references. The Low Noise Block downconverter (LNB) that is been used in reflector antennas, has a purpose to down convert the
10.7 $\mathrm{GHz}$ to $12.7 \mathrm{GHz}$ frequency range to an intermediate frequency (IF) in the 1-2 GHz range. These devices are now available as a single integrated circuit, instead of discrete components. The relative simplicity of this device, allow a number of them to be used as downconverters for small groups of sub arrays, thus minimising the losses of the $K_{u}$ band beam forming networks. The electronic beam steering is then carried out at the low frequency $(1-2 \mathrm{GHz}) \mathrm{IF}$, where any losses here have minimal impact on the overall performance of the antenna.

In this paper we present a flat $\mathrm{K}_{\mathrm{u}}$ band antenna which incorporates a fixed elevation squint and also has the ability for electronic beam steering in azimuth. This allows it to be mounted vertically on a wall that is in reasonable field of view of the satellite. The antenna can then be mounted discretely on structures such as apartment blocks or listed buildings which do not permit installation of reflector antennas.

\section{SYSTEM ARCHITECHTURE}

The $\mathrm{K}_{\mathrm{u}}$ band array, compared to a $45 \mathrm{~cm}$ reflector antenna, is shown in Fig. 1(a), the block diagram in Fig. 1(b). The antenna is comprised of $16 \times 16$ dual linear polarised microstrip patch elements, with each column of patches arranged as a sub array fed by a passive stripline beam forming network. The passive beamforming network was designed to give a phase distribution to allow the resultant subarray to have a fixed vertical squint of $23^{\circ}$, thus allowing the antenna to be placed in a vertical orientation. This vertical squint was designed to be suitable for the Astra satellite UK coverage beam. Also by fixing the steering angle in one plane greatly simplifies the number of beam steering circuits, i.e. 16 circuits, rather than 256 which would be needed for full azimuth/elevation steering.

Due to the weak received signal levels, the noise figure produced at the antenna is critical, in order to maintain an acceptable signal to noise ratio at the receiver. To address this, each subarray is first fed directly to a low noise amplifier since, as is classically known, it is essential that the LNA is positioned as close as possible to the antenna feed point to overcome feed losses, thus providing the lowest possible noise figure on receive. The LNA output is then fed 
to a downconverter IC (NXP TFF1018HN) which converts the $\mathrm{Ku}$ band signal of $10.7-12.7 \mathrm{GHz}$ to an IF signal in the range of 0.95 to $2.1 \mathrm{GHz}$ (two switched LOs of $9.75 \mathrm{GHz}$ or $10.6 \mathrm{GHz}$ are used such that the entire RF bandwidth of 2 $\mathrm{GHz}$ can be covered in a $1 \mathrm{GHz}$ wide IF band). The IF outputs are then summed via a passive power combiner. The advantage of this IF beamforming method is twofold. First the losses in the passive power combiner are less critical at the lower IF frequency, since the signal at this point has a reasonably high $\mathrm{S} / \mathrm{N}$ ratio. Secondly the IF produced is directly compatible with current DVB set top boxes, allowing ON-air tests to be readily carried out. The phase shifting of the received signal required to achieve azimuth steering is carried out by varying the phase of the $9.75 / 10.7$ $\mathrm{GHz}$ LO signals for each of the 16 subarrays.

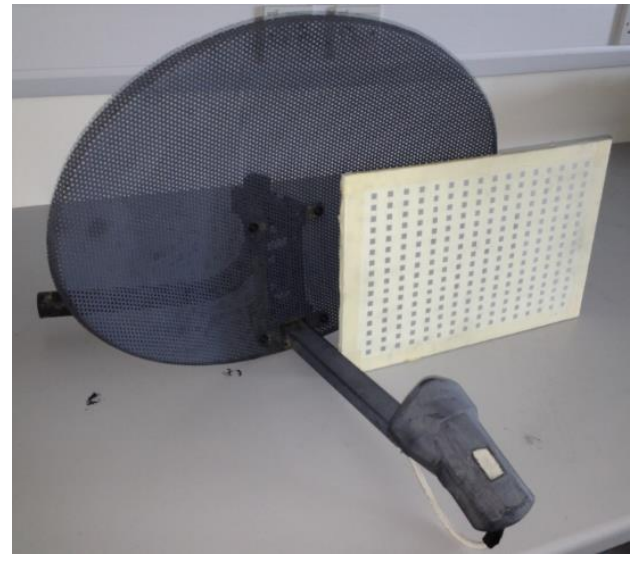

(a) $\mathrm{Ku}$ band array, compared to a $45 \mathrm{~cm}$ reflector antenna

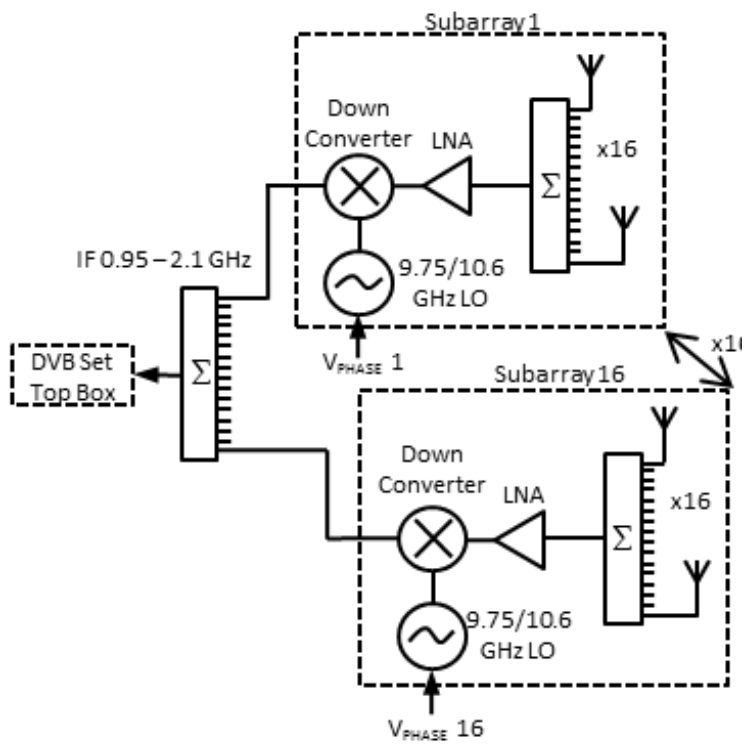

(b) Block diagram

Fig. 1. Ku band array

\section{PATCH ANTENNA ARRAY}

The patch antenna array was designed using CST microwave studio software. The large bandwidth of 10.7-
12.75 $\mathrm{GHz}$ (17\% bandwidth) produces challenges in the array design. The patches were required to maintain a high polarisation isolation specification $(>10 \mathrm{~dB})$ over this large bandwidth. This ruled out the possibility of using patch antennas directly placed on a medium to high dielectric constant substrate material, since these usually exhibit fairly narrow bandwidths. To achieve the $17 \%$ bandwidth required, the layer stack structure of Fig. 2 was used. This employs a spacer layer of ROHACELL foam. A feeding patch was placed in Layer 4, and another layer of parasitic antenna patches was placed on the top layer (Layer 1). Layer 6 was used as a ground plane for the feeding patches, and between layer 6 and layer 10, was placed the passive stripline beamforming network for the 16 element subarrays. Behind the patch array, on layer 12, was placed the phase shifting down converters and low noise amplifiers. The overall design allowed for the challenging $17 \%$ bandwidth requirements to be met in terms of adequate return loss, whilst also maintaining other important factors over the entire 10.7-12.7 GHz band, such as cross polar isolation, and port to port isolation.

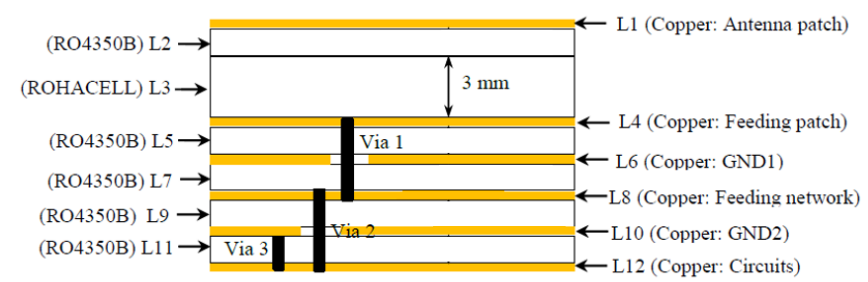

Fig. 2. Layer stack REMOVE R04350B from diag

\section{MEASURED RESULTS}

\section{A. Radiation Pattern Measurements}

The antenna array elevation and azimuth radiation far field patterns were measured in a $10 \mathrm{~m}$ anechoic chamber. First, the elevation pattern was required to be measured to confirm that the subarrays were producing the required $23^{\circ}$ beam squint in the elevation plane. Subsequent azimuth measurements were then carried out employing cuts through this optimum elevation angle. The elevation radiation pattern for a typical single subarray is shown in Fig. 3. Here it is observed that the elevation squint exhibits excellent agreement with simulation conducted using CST software, with $23^{\circ}$ measured and $22^{\circ}$ simulated. Cross polar isolation between vertical and horizontal polarisation was measured as $>20 \mathrm{~dB}$, simulated $>25 \mathrm{~dB}$. The beamwidth of the subarray is also in excellent agreement with the simulation, confirming that the entire subarray, including patch elements has been predicted accurately. 


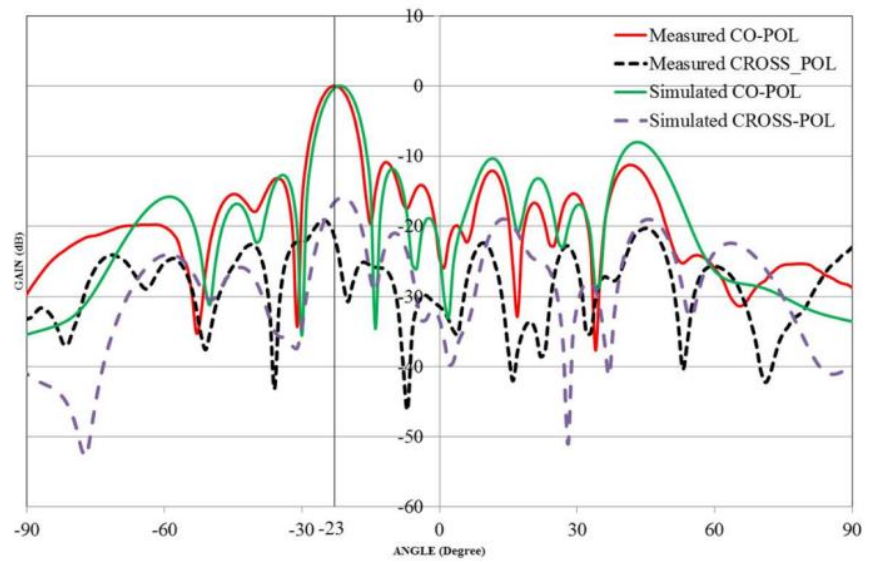

Fig. 3. Simulated and measured Normalised Elevation radiation pattern of single subarray

The radiation patterns of the array were now measured in azimuth to confirm the beam steering capability of the array. The array was mounted in the anechoic chamber with a fixed elevation of angle of $23^{\circ}$, the optimum value obtained from the elevation measurement. Progressive phases were setup across the array to provide beam steering. Fig. 4 shows azimuth beam steering achieved for vertical polarisation over the range of $\pm 20^{\circ}$. Pointing loss was $<1 \mathrm{~dB}$ over the azimuth steering range of $\pm 10^{\circ}$, increasing to $<3 \mathrm{~dB}$ over the azimuth steering range of $\pm 20^{\circ}$. Cross polarisation isolation was measured to be $>18 \mathrm{~dB}$ at boresight.

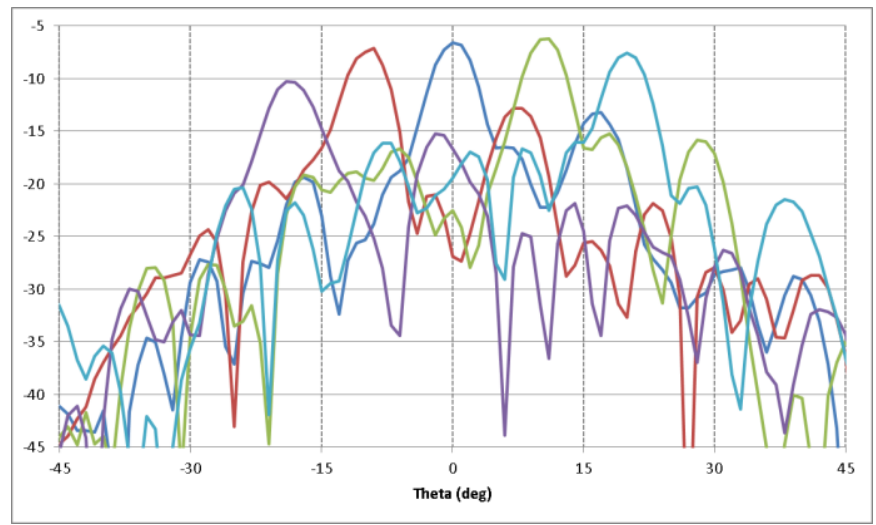

Fig. 4. Azimuth steered radiation patterns - vertical polarisation

\section{B. G/T Measurements}

Here, we have measured the G/T of the Ku band array and benchmarked against a $45 \mathrm{~cm}$ diameter $\mathrm{Ku}$ band reflector antenna. The two antennas are shown in Fig. 1(a). The G/T of the antennas was measured in a $10 \mathrm{~m}$ anechoic chamber. The method used employed a spectrum analyser to measure the $\mathrm{C} / \mathrm{N}_{0}$ of the received IF signal, with a known power density carrier signal being transmitted to the antenna under test. Minor corrections were required to allow for the fact that the $\mathrm{C} / \mathrm{N}_{0}$ obtained in an anechoic chamber is lower than clear sky conditions [5], due to the anechoic chamber having a higher noise temperature. The $\mathrm{G} / \mathrm{T}$ was then calculated using:

$G / T(d B / K)=$ Carrier power density $(d B m)+k(d B)+C / N_{0}(d B H z)$

Where Boltzmann constant $\mathrm{k}=-228.6 \mathrm{~dB}$, Carrier power density was set at $-110.7 \mathrm{dBm}$.

The measurements yielded a value of $\mathrm{G} / \mathrm{T}=7 \mathrm{~dB} / \mathrm{K}$ for the $\mathrm{K}_{\mathrm{u}}$ band array and $12.6 \mathrm{~dB} / \mathrm{K}$ for the, larger aperture, $45 \mathrm{~cm}$ diameter $K_{u}$ band reflector antenna. The $G / T$ of 7 $\mathrm{dB} / \mathrm{K}$ for the aperture size of $25 \times 37 \mathrm{~cm}$ compares favourably when benchmarked with other flat array antennas. An example of this is [6] which reports a $\mathrm{G} / \mathrm{T}$ of $13 \mathrm{~dB} / \mathrm{K}$ for an aperture with 3.5 times $(5.5 \mathrm{~dB}$ increase $)$ the surface area (40x80cm).

\section{DVB Reception Measurements}

The $\mathrm{Ku}$ band array has been verified to be able to successfully receive, and demodulate (via a DVB set top box) a $K_{u}$ band satellite DVB signal. The measurements were carried out in two locations (Belfast and Harwell, UK ADD LAT LONG for both sites) to prove successful performance with regional variations. The satellite signal used was from the Astra 2 satellite located at $28.2^{\circ}$ east, which offers a UK coverage beam with a satellite EIRP of $54 \mathrm{dBW}$, typically requiring a $50 \mathrm{~cm}$ diameter reflector antenna for error free reception in all weather conditions. Fig. 5 (a) shows that in the Belfast location the antenna is orientated vertically, since the $23^{\circ}$ elevation squint is almost a perfect match for the Astra 2 satellite elevation in this location. In Fig. 5 (b), in Harwell, UK, the satellite elevation has increased by several degrees, which is evident from the slight upward tilt of the antenna. In both locations a good range of $\mathrm{K}_{\mathrm{u}}$ band satellite DVB signals were successfully demodulated using a DVB set top box.

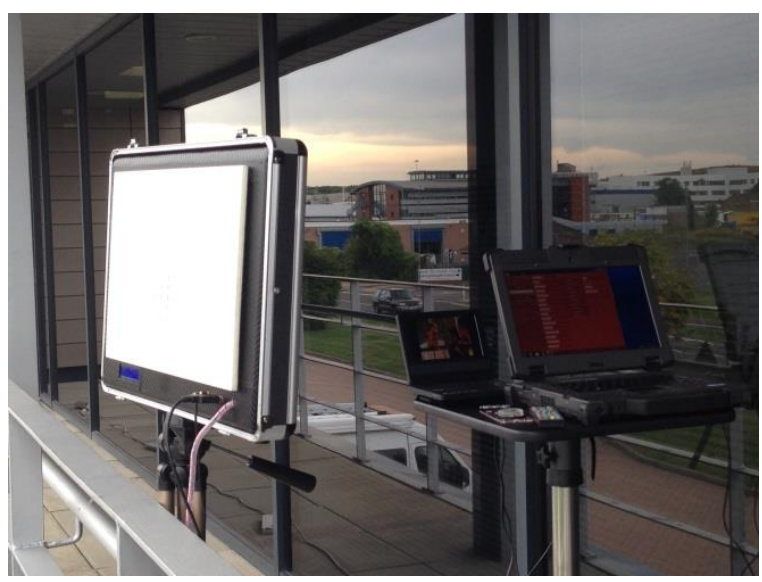

Fig. 5. Ku band prototype DVB antenna on air testing.

\section{CONCLUSIONS}

A 256 element patch antenna array has been demonstrated at $\mathrm{Ku}$ band to meet the demanding requirement to allow reception of $\mathrm{Ku}$ band DVB satellite signals without the need for manual alignment. The antenna has been 
practically verified to have a $23^{\circ}$ elevation squint, allowing it to be mounted vertically for discrete operation. Electronic beam steering in the azimuth plane has been measured to be $\pm 20^{\circ}$. The antenna panel measures $25 \times 37 \mathrm{~cm}$ and is able to produce a sufficient $\mathrm{G} / \mathrm{T}$ to allow the satellite reception link budget to be met in clear sky conditions.

\section{ACKNOWLEDGMENT}

The authors would like to acknowledge the support of the Invest Northern Ireland Proof of Concept Programme PoC339. We would like to acknowledge the Satapps Catapult Centre, Harwell, for hosting the on-site measurements. Also many thanks to Mr Michael Major and $\mathrm{Mr}$ Kieran Rainey for fabricating and measuring the prototypes.

\section{REFERENCES}

[1] http://www.telegraph.co.uk/finance/newsbysector/mediatechnologyan dtelecoms/media/8359194/News-Corp-clears-way-for-BSkyB-bidwith-plan-to-spin-off-Sky-News.html Accessed 10-8-16

[2] M. C. D. Maddocks and M. S. Smith, "A steerable flat-plate antenna design for satellite communications and broadcast reception," Antennas and Propagation, 1989. ICAP 89., Sixth International Conference on (Conf. Publ. No.301), Coventry, 1989, pp. 40-44 vol.1.

[3] A. Henderson and J. R. James, "Low-cost flat-plate array with squinted beam for dbs reception," in IEE Proceedings $\mathrm{H}$ Microwaves, Antennas and Propagation, vol. 134, no. 6, pp. 509-514, December 1987.

[4] A. Toshev, E. Totomanov, M. Gatchev, B. Marinov, I. Stoyanov and S. Kamenopolsky, "Flat Limited Scanning Phased Array Antenna for DBS Reception," Microwave Conference, 2002. 32nd European, Milan, Italy, 2002, pp. 1-4.

[5] R. Wansch, "A method for measuring G/T antenna performance in an anechoic chamber," 2009 3rd European Conference on Antennas and Propagation, Berlin, 2009, pp. 2212-2215.

[6] 6. R. Vincenti Gatti, L. Marcaccioli, E. Sbarra and R. Sorrentino, "Flat array antenna for Ku-band mobile satellite terminals," Proceedings of the 5th European Conference on Antennas and Propagation (EUCAP), Rome, 2011, pp. 2618-2622. 